\title{
NUTRITION THERAPY IN THE TREATMENT OF OVERWEIGHT AND OBESE ADULTS WITH TYPE 2 DIABETES
}

\author{
Razvan Vasilescu, MD \\ Department of Diabetes, Nutrition and Metabolic Diseases, Clinical Hospital Colentina, Bucharest
}

\begin{abstract}
It is well known the role of diet in the management of overweight and obese type 2 diabetic patients. Even a modest weight loss ( $5 \%$ to $10 \%$ of total body weight) is associated with improvements of cardiovascular risk factors. The traditional recommendations regarding the intake of macronutrients are: carbohydrate intake $45 \%$ to $65 \%$ of total energy, a total fat intake $\leq 35 \%$ of total energy (with reduction of saturated and trans fat intake and increase monounsaturated fatty acids intake) and protein intake $15 \%$ to $20 \%$ of total energy. The recent guidelines recommend increased flexibility in macronutrient composition. In this article I present different dietary patterns (such as low carbohydrate diets, high protein diets, low calorie diets, very low calorie diets and Mediterranean diet) used in the management of type 2 diabetic patients, their effects on short-term outcomes as well as on long-term outcomes. Energy restriction is required for weight loss. In short-term trials high-protein, low-carbohydrate diets are more favorable for weight loss than traditional high-carbohydrate, low-fat diets. Very important in weight loss and metabolic control are the adherence to a diet and pharmacotherapy. Recently probiotic and prebiotic have been proposed as a new treatment strategy.
\end{abstract}

Keywords: diabetes, obesity, diet, weight-loss

\section{INTRODUCTION}

Medical nutrition therapy (MNT) is an essential component of preventing diabetes, managing existing diabetes and preventing and slowing diabetes complications. (1) Prospective Studies Collaboration which analysed a number of approximately 900,000 adults included in 57 prospective studies showed that each $5 \mathrm{~kg} / \mathrm{m}^{2}$ higher body mass index (BMI) above $25 \mathrm{~kg} / \mathrm{m}^{2}$ was associated with about $30 \%$ higher overall mortality: $40 \%$ for vascular mortality, $60 \%$ to $120 \%$ for diabetes, renal and hepatic mortality, $10 \%$ for neoplastic mortality and $20 \%$ for respiratory and for all other mortality. (2) Cerhan et al. (3) showed that higher waist circumference was positively associated with high mortality at all levels of BMI from 20 to $50 \mathrm{~kg} / \mathrm{m}^{2}$. According to this study the estimated decrease in life expectancy for highest vs. lowest waist circumfer- ence was approximately 3 years for men and approximately 5 years for women. Studies investigating dietary strategies for weight loss have utilized many different diets, such as: low fat diets, low carbohydrate diets, high protein diets, balanced deficit diets, very low calorie diets (VLCD) and Mediterranean diet. Also portion control and meal replacement have proved effective in weight management.

\section{Effectiveness of MNT in type 2 diabetes}

About 80 to 90 percent of people with type 2 diabetes are overweight or obese. (4) MNT can reduce $\mathrm{HbA} 1 \mathrm{c}$ by $1 \%$ to $2 \%$ depending on the type, duration of diabetes and the $\mathrm{HbA} 1 \mathrm{c}$ value at baseline. $(5,6)$ Weight loss in type 2 diabetic patients is associated with markedly reduce plasma glucose concentration, reduction in fasting insulin levels, 
reduced cardiovascular risk factors (reduction in blood pressure and improvements in lipid profile), increased insulin sensitivity and improvement in well-being of the patients. (7-10) Williamson et al. (11) showed in overweight people with diabetes that intentional weight loss of $11 \%$ of initial body weight was associated with $25 \%$ reduction in mortality. Petersen et al. (8) showed in eight obese patients with type 2 diabetes that a moderate weight loss normalizes fasting hyperglycemia, reverses hepatic steatosis and hepatic insulin resistance and normalizes basal rates of hepatic glucose production by decreasing gluconeogenesis.

In patients with newly diagnosed type 2 diabetes the initial period post diagnosis is a critical time for weight-loss. Feldstein et al. (12) showed in newly diagnosed type 2 diabetic patients that a weight loss of $9.8 \%$ predicted improved glycemic and blood pressure control despite weight regain in year 4 compared to patients who maintained their weight or gained weight post diagnosis.

According to the guideline for the management of overweight and obesity in adults elaborated in 2013 by the American College of Cardiology / American Heart Association and The Obesity Society (ACC/AHA/TOS) lifestyle changes that produce even a modest weight loss of $3-5 \%$ produce clinically meaningful reductions in triglycerides, blood glucose, glycated hemoglobin (HbAlc) and the risk of developing type 2 diabetes and greater weight losses produces greater benefits (reduce blood pressure, improve LDL-C and HDL-C, and reduce the need for medications to control blood pressure, blood glucose and lipids as well as further reduce triglycerides and blood glucose). (13)

Look AHEAD is both the largest and the longest randomized evaluation to date of an intensive lifestyle intervention for weight management. (14) Look AHEAD study evaluated in overweight or obese patients with type 2 diabetes the long-term effects of an intensive lifestyle intervention program for weight loss by decreased caloric intake and increased physical activity compared to a program of diabetes support and education. The study which included a number of 5,145 participants showed at one year that patients in the lifestyle intervention program lost $8.6 \%$ of their body weight compared to $0.7 \%$ in the control arm. At the study's completion the mean weight loss from baseline was $6 \%$ in the lifestyle intervention group compared to $3.5 \%$ in the control group (15). After a median follow-up of 9.6 years the Look AHEAD study showed that the intensive lifestyle intervention did not reduce the rate of cardiovascular events. (16) The in- tensive lifestyle intervention was associated with partial remission of type 2 diabetes (17), a reduction of the rate of sleep apnea (18), slow the decline in mobility (19) and improvements in health-related quality of life. (20)

\section{Medical nutrition therapy in the prevention of diabetes}

Medical nutrition therapy has been shown to be effective in the prevention of type 2 diabetes. $(21,22)$ Patients at high risk for the development of type 2 diabetes should implement lifestyle interventions to achieve a minimum of $7 \%$ weight loss followed by weight maintenance, and a minimum of 150 minutes of weekly physical activity, similar in intensity to brisk walking. (23) The Diabetes Prevention Program (DPP) which included a number of 3,234 adults at high risk for the development of type 2 diabetes (mean age of the participants was 51 years and the mean BMI was $34 \mathrm{~kg} / \mathrm{m}^{2}$ ), demonstrated that the incidence of type 2 diabetes was reduced by $58 \%$ with an intensive program of lifestyle modification and by $31 \%$ with metformin, over an average follow-up of 2.8 years (21). Li et al. (22) showed in Da Qing Diabetes Prevention Study which included 577 patients that a 6 year lifestyle intervention in people with impaired glucose tolerance reduce incidence of cardiovascular and all-cause mortality and diabetes after 23 years.

According to ACC/AHA/TOS in overweight and obese adults at risk for type 2 diabetes, average weight losses of $2.5 \mathrm{~kg}$ to $5.5 \mathrm{~kg}$ at $\geq 2$ years, achieved with lifestyle intervention (with or without orlistat) reduces the risk of developing type 2 diabetes by $30 \%$ to $60 \%$. (13)

\section{Nutrition guidelines}

All obesity management recommendations include diet, physical activity and behavioral modification. The ACC/AHA/TOS (13) recommendations for weight loss are: 1) recommendations regarding diets for weight loss: a) 1,200-1,500 kcal/day for women and 1,500-1,800 kcal/day for men; b) 500 $\mathrm{kcal} /$ day or $750 \mathrm{kcal} /$ day energy deficit; c) one of the evidence-based diets that restricts certain food types, such as high carbohydrate foods, low-fiber foods or high fat foods; 2) recommendations regarding comprehensive lifestyle intervention: a) individuals should be advised to participate for $\geq 6$ months in a comprehensive lifestyle program; b) some commercial-based programs that provide a comprehensive lifestyle intervention can be prescribed as an option for weight loss; c) very low 
calorie diet are indicated only in limited circumstances; d) advice individuals who have lost weight to participate long time ( $\geq 1$ year) in a comprehensive weight loss maintenance program; e) strategies such as frequent self-weighing (at least weekly), consumption of a reduced caloric diet and high levels of physical activity.

Several international societies, such as Diabetes and Nutrition Study Group (DNSG) of the European Association for the Study of Diabetes (EASD), American Diabetes Association (ADA), American Association of Clinical Endocrinologists (AACE) / The American College of Endocrinology (ACE) and The Obesity Society, Canadian Diabetes Association, Diabetes UK have developed recommendations regarding the nutritional management of patients with diabetes and for the prevention and treatment of metabolic and endocrine diseases in adults (Table 1). Most nutritional guidelines recommend diets high in carbohydrates $(45-65 \%$ of total energy intake) and low in fat $(<35 \%$ of total energy intake).

AACE/ACE and Obesity Society (25) recommendations for overweight and obese subjects are: nutrition counseling should be culturally, linguistically and educationally; the weight-loss goal should be 5 to $10 \%$ of current body weight over the following 6 to 12 months; combined therapy utilizing a low-calorie diet (LCD) with a deficit of 500 to $1,000 \mathrm{kcal} /$ day, increased physical activity, behavior therapy, and appropriate pharmacotherapy provides the most successful intervention for weight loss and weight maintenance; a gradual weight-loss of 0.5 to $1 \mathrm{~kg} /$ week. According to the Diabetes UK 2011 (26) guideline low-carbohydrate diets may be considered an option for weight loss in people with type 2 diabetes when supported by a registered healthcare professional, weight management should be person-centred approach and each individual should be supported to follow the weight loss programme they find most acceptable. Canadian Diabetes Association (5) nutrition therapy recommendations are: replacing high glycemic index carbohydrates with low glycemic index carbohydrates; higher intakes of dietary fiber than those recommended for the general population; weight management program should provide individualized nutritional, physical activity and behavioral programs; weight-loss diets must be nutritionally balanced, a carbohydrate intake of at least $100 \mathrm{~g} /$ day is required to spare protein breakdown and muscle wasting, adequate protein intake is required to maintain lean body mass; very low calorie diets with $<900 \mathrm{kcal} /$ day are not recommended.

\section{High-protein diets}

Studies which evaluated high-protein diets demonstrated that these diets produce greater shortterm weight loss, similar long-term weight loss and better improvement in some cardiovascular risk factors (such as insulin resistance, triglyceride, HDL-cholesterol) compared with a low-fat diet. (28) Foster et al. (29) showed in a randomized trial which enrolled 63 obese men and women (patients

TABLE 1. Nutritional recommendations from various organisations

\begin{tabular}{|c|c|c|c|c|}
\hline Society & \begin{tabular}{|l|} 
Protein intake \\
(\% of total energy)
\end{tabular} & $\begin{array}{l}\text { Fat intake } \\
\text { (\% of total energy) }\end{array}$ & \begin{tabular}{|l|}
$\begin{array}{l}\text { Carbohydrate intake } \\
\text { (\% of total energy) }\end{array}$ \\
\end{tabular} & Other recommendations \\
\hline EASD (2004) (23) & $10-20 \%$ & $\begin{array}{l}<35 \% \\
\text { (saturated and trans- } \\
\text { unsaturated fatty acid } \\
<10 \%, \text { MUFA: } 10- \\
20 \%, \text { PUFA }<10 \% \text { and } \\
\text { cholesterol }<300 \text { g/day) }\end{array}$ & $45-60 \%$ & $\begin{array}{l}\text { - dietary fibre intake } \\
>40 \mathrm{~g} / \text { day (or } 20 \mathrm{~g} / 1,000 \\
\text { kcal/day); } \\
\text { - there is no justification } \\
\text { for very low carbohydrate } \\
\text { diet }\end{array}$ \\
\hline ADA (2013) (24) & $\begin{array}{l}\text { There is not an ideal } \\
\text { percentage of calories }\end{array}$ & $\begin{array}{l}\text { There is not an ideal } \\
\text { percentage of calories }\end{array}$ & $\begin{array}{l}\text { There is not an ideal } \\
\text { percentage of calories }\end{array}$ & \begin{tabular}{|l} 
- dietary fibre intake: \\
$14 \mathrm{~g} / 1,000 \mathrm{kcal} /$ day \\
\end{tabular} \\
\hline $\begin{array}{l}\text { AACE/ACE and } \\
\text { Obesity Society } \\
\text { (2013) (25) }\end{array}$ & $\begin{array}{l}15-35 \% \\
(0,8-1 \mathrm{~g} / \mathrm{kg} / \text { day) } \\
\text { (include reduced-fat } \\
\text { animal protein and } \\
\text { reduced-fat dairy protein) }\end{array}$ & $\begin{array}{l}25-35 \% \\
\text { (saturated fat < 7\%, MUFA: } \\
15-20 \%, \text { PUFA < } 10 \% \text { and } \\
\text { cholesterol < } 200 \text { g/day ) }\end{array}$ & $\begin{array}{l}45-65 \% \\
\text { (limit sugar or foods that } \\
\text { have a high glycemic } \\
\text { index) }\end{array}$ & $\begin{array}{l}\text { - dietary fibre intake: } \\
\text { 20-35 g/day } \\
\text { (or } 14 \text { g / 1,000 kcal/day) }\end{array}$ \\
\hline \begin{tabular}{|l|} 
Canadian Diabates \\
Association (2013) (5)
\end{tabular} & $15-20 \%(1-1.5 \mathrm{~g} / \mathrm{kg} / \mathrm{day})$ & $\begin{array}{l}20-35 \% \\
\text { (saturated fat }<7 \% \text {, MUFA: } \\
\text { up to } 20 \% \text {, PUFA up to } \\
10 \% \text { ) }\end{array}$ & $45-60 \%$ & $\begin{array}{l}\text { - dietary intake: } \\
25-50 \mathrm{~g} / \text { day } \\
\text { (or } 15-25 \mathrm{~g} / 1,000 \mathrm{kcal} \text { ) }\end{array}$ \\
\hline $\begin{array}{l}\text { Diabetes UK (2011) } \\
(26,27)\end{array}$ & not $>1 \mathrm{~g} / \mathrm{kg}$ & $\begin{array}{l}<35 \% \\
\text { (saturated and } \\
\text { transunsaturated }<10 \% \text {, } \\
\text { n-6 PUFA }<10 \% \text {, MUFA: } \\
10-20 \% \text { ) }\end{array}$ & $\begin{array}{l}\text { Active carbohydrate } \\
\text { management rather than } \\
\text { prescribing absolute } \\
\text { intakes }\end{array}$ & $\begin{array}{l}\text { - no quantitative } \\
\text { recommendation for } \\
\text { dietary fiber }\end{array}$ \\
\hline
\end{tabular}


with diabetes were excluded) that a high-protein/ low-carbohydrate diet produced a greater weight loss than a conventional diet (high-carbohydrate/ low-fat/low-calorie diet $-1,200$ to $1,500 \mathrm{kcal} /$ day for women and 1,500 to $1,800 \mathrm{kcal} /$ day for men, with approximately $60 \%$ of calories from carbohydrate, $25 \%$ from fat and $15 \%$ from protein) for the first six months, but the differences were not significant at one year.

Santesso et al. (30) showed in a meta-analysis which compared the effects of higher-protein (median protein content was $27 \%$ of the total energy intake - range: $16-45 \%$ ) versus lower-protein (median protein content was $18 \%$ of the total energy intake - range: 5-23\%) diets that higher-protein diets were associated at 3 months with greater weight loss $(1.21 \mathrm{~kg})$, a greater decrease in BMI $(-0.51 \mathrm{~kg} /$ $\left.\mathrm{m}^{2}\right)$ and a greater loss in waist circumference (-1.66 $\mathrm{cm})$, improve blood pressure, HDL-cholesterol and triglycerides levels, but these effects were small.

Gannon et al. (31) showed that a high-protein/ low-carbohydrate diet, weight-maintaining, nonketogenic $(2,825 \mathrm{kcal}$, protein $-30 \%$, carbohydrate $20 \%$ and fat $-50 \%$ ) compared to a control diet $(2,825 \mathrm{kcal}$, protein $-15 \%$, carbohydrate $-55 \%$ and fat $-30 \%$ ) over a 5 weeks period was associated with a dramatic improvement in metabolic control (fasting glucose concentration decreases from $167 \pm 13 \mathrm{mg} / \mathrm{dl}$ to $119 \pm 7 \mathrm{mg} / \mathrm{dl}$, mean glucose concentration was reduced from $198 \mathrm{mg} / \mathrm{dl}$ to 126 $\mathrm{mg} / \mathrm{dl}$ and $\mathrm{HbA} 1 \mathrm{c}$ concentration decrease from a mean of $9.8 \%$ to $7.6 \%$ ) in untreated patients with type 2 diabetes.

The potential mechanisms involved in weightloss associated with high-protein diets are: increased secretion of gut hormones that induce satiation (such as gastric inhibitory polypeptide - GIP, glucagon-like peptide-1 - GLP-1, cholecystokinin - CCK, peptide YY-PYY), reduced orexigenic hormone secretion (such as ghrelin), increased thermic effect of food and protein-induced alterations in gluconeogenesis to improve glucose homeostasis (32). Veldhorst et al. (33) demonstrated that after a high-protein diet there is no correlation between gluconeogenesis and appetite suppression. The authors suggested that the increased concentration of ketone bodies ( $\beta$-hydroxybutyrate) may have contributed to the appetite suppressive effect of highprotein diet.

\section{Low-carbohydrate diets}

Many studies reported that low-carbohydrate diets have benefits for weight loss, treatment of type
2 diabetes and cardiovascular disease. There is no accepted definition for low-carbohydrate diet. Diabetes UK uses the term „low-carbohydrate“" as a collective term to describe any amount of carbohydrate restriction which is less than the dietary reference value of $45 \%$ of total energy. (34) The 2008 ADA guidelines recommend a minimum of $130 \mathrm{~g} /$ day of carbohydrate. (35) The new ADA guidelines don't have this recommendation. (24) According to Wheeler et al. (36) the following definitions are used for carbohydrate content of different diets: very low-carbohydrate diet content 21-70 g/day of carbohydrate; moderate low-carbohydrate diet content $30-40 \%$ of kcal as carbohydrate; moderatecarbohydrate diet content $40-65 \%$ of kcal as carbohydrate and high-carbohydrate diet content $>65 \%$ of kcal as carbohydrate. Accurso et al. (37) suggested the following definitions: very low-carbohydrate ketogenic diet (VLCKD) content $<30 \mathrm{~g}$ /day of carbohydrate; low-carbohydrate diet content $<130 \mathrm{~g}$ /day of carbohydrate (or $<26 \%$ of kcal as carbohydrate of a 2,000 kcal diet); moderate-carbohydrate diet content $26 \%$ to $45 \%$ as carbohydrate of a $2,000 \mathrm{kcal}$ diet.

Nielssen et al. (38) showed in 16 obese patients with type 2 diabetes that after 6 months a low-carbohydrate diet consisted of $20 \%$ carbohydrates, $30 \%$ protein and $50 \%$ fat, compared with a control diet about the same caloric content consisted of $60 \%$ carbohydrates, $15 \%$ protein and $25 \%$ fat was associated with better glycemic control (HBA1c: $-1.4 \pm 1.1 \%$ and $-0.6 \pm 1.4 \%)$ and greater weight loss (body weight: $-11.4 \pm 4 \mathrm{~kg}$ and $-1.8 \pm 3.8 \mathrm{~kg}$; BMI: $-4.1 \pm 1.3 \mathrm{~kg} / \mathrm{m}^{2}$ and $-0.7 \pm 1.3 \mathrm{~kg} / \mathrm{m}^{2}$ ). Large changes in blood glucose levels were seen immediately. The authors also showed that these changes were preserved in the low-carbohydrate group after 44 months observation time. (39)

Guldbrand et al. (40) evaluated the effects of a 2 year intervention with a low-carbohydrate diet (LCD - consisted of $20 \%$ carbohydrate, $30 \%$ protein and $50 \%$ fat) or a low-fat diet (LFD - consisted of $55-60 \%$ carbohydrate, $10-15 \%$ protein and $30 \%$ fat) in 61 adults with type 2 diabetes (BMI $32.7 \pm 5.4 \mathrm{~kg} / \mathrm{m}^{2}$ ). Both diets have the same energy content $1,600 \mathrm{kcal} /$ day for women and $1,800 \mathrm{kcal} /$ day for men. The study found that weight loss did not differ between groups and was maximal at 6 months: LFD $-3.99 \pm 4.1 \mathrm{~kg}$; LCD $-4.31 \pm 3.6 \mathrm{~kg}$. At 24 months, patients on the LFD lost $-2.97 \pm 4.9$ $\mathrm{kg}$ and those on LCD $-2.34 \pm 5.1 \mathrm{~kg}$ compared with baseline. At 6 months in LCD were seen the following results: a significant reduction in $\mathrm{HbA} 1 \mathrm{c}$, a significant reduction in insulin doses and significant increase in HDL-cholesterol concentrations. 
In clinical practice there are controversies regarding low-carbohydrate diets in patients with diabetes because of concerns about their safety, effectiveness and sustainability, along with their impact on the kidneys, bones, lipids, and thyroid (41). In 2013, after a two years review of 16.000 scientific studies of diet, the Swedish Council on Health and Technology Assessment has recommended a low carbohydrate, high fat diet for people who are overweight or obese or have diabetes. (42)

\section{Low-calorie diets (LCDs) and very low-calorie diets (VLCDs)}

LCD is defined as a diet with an energy content between 800 to $1,200 \mathrm{kcal} /$ day and VLCD is defined as diet replacement with an energy content between 400 or 450 to $800 \mathrm{kcal} /$ day. (43) There has been a long history of debate over the use of VLCDs in clinical practice. (44) From a historical perspective VLCDs used in the " 70 s were associated with a number of death probably due to vitamin and mineral deficiencies and poor quality or inadequate amounts of protein. $(43,45)$ There are now a number of commercially available VLCDs (such as Optifast VLCD, Optisilim, KicStart VLCD, Slimfast, Cambridge, Eurodiett, Nutrilett) which are designed to provide at least $50 \mathrm{~g}$ of high quality protein to preserve lean body mass and all vitamins and minerals at recommended daily allowance levels. $(24,26)$ While LCDs are indicated for most patients, VLCDs should be used only in obese subjects with significant comorbidities. $(23,46,47)$ VLCDs are used to induce rapid weight loss. $(48,49)$ They can produce weight losses up to 1.5 to $2.5 \mathrm{~kg} /$ week and up to $20 \mathrm{~kg}$ in 12 to 16 weeks. (50) Also, VLCDs may be used intermittently with a LCD (for 2-4 days a week), by people who are obese and have reached a plateau in weight loss. (51)

VLCDs require nutritional supplementation and medical monitoring for complications such as, electrolyte imbalances, hepatic transaminase elevation, gout and gallstone formation and the duration of treatment should not exceed 12 to 16 weeks. $(23,47)$ According to Norwegian Scientific Committee for Food Safety, VLCD products should provide minimum $55 \mathrm{~g}$ carbohydrates, $10 \mathrm{~g}$ fibres, $50 \mathrm{~g}$ high quality protein and $7 \mathrm{~g}$ fat, including $3 \mathrm{~g}$ from linoleic and $0.5 \mathrm{~g}$ from $\alpha$-linoleic acid. There are no maximum limits for macronutrients composition as the energy is the limiting factor, the fibre content should not exceed $30 \mathrm{~g}$ per day and the maximum limits for vitamins and minerals should equal two times the recommended daily intake. (52) In 2011, the European Food Safety Authority has approved a health claim regarding the efficacy of VLCDs on weight loss in a target population of obese adults. (53) Indications for VLCDs are: well-motivated individuals who are moderately to severely obese, have failed other nutritional approaches to weight loss and have a medical condition that is immediately improved with rapid weight loss (such as, poorly controlled type 2 diabetes, joint replacement surgery, subjects seeking fertility services, obstructive sleep apnea and symptomatic peripheral edema. $(23,47,54)$

VLCDs are associated with improvement in blood pressure, serum lipids and glycemia in obese subjects with type 2 diabetes (52). Capstick et al. (55) showed in 14 obese noninsulin dependent diabetes mellitus (NIDDM) patients with poor diabetic control that a VLCD (425 kcal /day) given for 12 weeks is very effective in rapidly improving glycaemic control and promoting substantial weight loss in obese NIDDM patients. Malandrucco et al. (56) showed in 14 severely obese patients with type 2 diabetes with $\mathrm{HbA} 1 \mathrm{c}<7.5 \%$ that after 7 days a VLCD (400 kcal/day) caused a $3.22 \pm 0.56 \%$ weight loss, $42 \%$ of which was fat loss accompanied by decrease in fasting plasma glucose and triglycerides. The study demonstrated that improvement in metabolic profile was due to the amelioration of $\beta$ cell function with no change in insulin sensitivity. Lara-Castro et al. (57) showed that after 6 days a VLCD containing $700 \mathrm{kcal} /$ day resulted in small decrements in general adiposity (minimal change in BMI and no statistically significant change in body fat) and marked decrease in intramyocellular lipid - IMCL - $(56 \%$ decrease in non-diabetics and $40 \%$ decrease in type 2 diabetic patients compared to baseline values) accompanied by increases in insulin sensitivity. The authors suggested that the rapid amelioration of insulin resistance by VLCD can be explained by loss of IMCL in the absence of important changes in total body fat. A review which evaluated the effects of VLCDs on high-density lipoprotein (HDL) levels showed that HDL levels usually decrease during active weight loss but either return to pre-VLCD levels or improve during the weight-maintenance phase. (58) Hammer et al. (59) showed in twelve obese, insulin-treated type 2 diabetes that a 16 -week VLCD (450 kcal/day) decreased BMI $\left(35.6 \pm 1.2 \mathrm{~kg} / \mathrm{m}^{2}\right.$ to $\left.27.5 \pm 1.3 \mathrm{~kg} / \mathrm{m}^{2}\right)$ and myocardial triglyceride content and improved diastolic function.

It is important to stress that there are studies which demonstrated that there is no significant difference in weight loss between diets with an energy 
content ranging from $420 \mathrm{kcal} /$ day to $880 \mathrm{kcal} /$ day. (60-62)

Johansson et al. (63) assessed the risk of symptomatic gallstones requiring hospital and/or cholecystectomy in a commercial weight loss program using VLCD of LCD. The weight loss program comprised an initial weight loss phase of VLCD (500 kcal/day) or LCD (1,200-1,500 kcal/day) followed by a 9 month weight maintenance phase. The study found that during the 1 year weight loss program the risk of gallstones as well as cholecystectomy was low but approximately three times higher in the VLCD group than in the LCD group. The larger prevalence of cholelithiasis could be decreased by the use of at least $7 \mathrm{~g}$ of essential fatty acids to stimulate gall bladder contractions. Other side effects of VLCDs are: dry mouse, constipation, headache, dizziness, orthostatic hypotension, fatigue, cold intolerance, dry skin, menstrual irregularities and hair loss. (43) Contraindications to VLCDs are: recent myocardial infarction, cardiac conduction disorder, history of cerebrovascular, renal or hepatic disease, type 1 diabetes mellitus, major psychiatric disorderes, gallbladder disease, alcoholism, cancer, infection, acute substance abuse, anorexia and human immunodeficiency virus. (46) Also VLCDs are contraindicated in children, adolescents, pregnant and lactating women and elderly (above 65 years old). (52)

\section{Long term effect of $V L C D s$}

The published results regarding weight loss maintenance after VLCDs are contradictories.

Dhindsa et al. (64) demonstrated in forty obese patients with type 2 diabetes and symptomatic hyperglycaemia despite combination oral therapy or insulin in association with metformin that 8 weeks of VLCD (750 kcal/day) followed by standard diet and exercise advice at 2-3 month intervals were associated at 8 weeks with significant weight loss (mean body weight $-119 \pm 19 \mathrm{~kg}$ vs. $107 \pm 18 \mathrm{~kg}$ and BMI $-40.6 \mathrm{~kg} / \mathrm{m}^{2}$ vs. $36.6 \mathrm{~kg} / \mathrm{m}^{2}$ ) and important reductions in serum total cholesterol, blood pressure and fructosamine. At 1 year patients had minimal weight regain (mean body weight $-109 \pm 18 \mathrm{~kg}$ and BMI $-37 \pm 4 \mathrm{~kg} / \mathrm{m}^{2}$ ) and a deterioration of glycaemic control. Hemmingson et al. (65) evaluated weight loss and the dropout rate after 1 year in a number of 9,037 subjects enrolled in a weight-loss program in Sweden. Weight loss was induced with a $500 \mathrm{kcal} /$ day VLCD, a 1,200-1,500 kcal/day LCD and a 1,500-1,800 kcal/day restricted normal-food diet, followed by a diet and exercise maintenance phase. After 1 year weight loss in VLCD group was
$-11.4 \pm 9.1 \mathrm{~kg}(18 \%$ dropout $)$, in LCD group was $-6.8 \pm 6.4 \mathrm{~kg}$ ( $23 \%$ dropout) and in restricted normal-food group $-5.1 \pm 5.9 \mathrm{~kg}$ ( $26 \%$ dropout).

In a recent article published in October 2014, Purcell et al. (66) showed that the rate of weight loss does not affect the proportion of weight loss within 144 weeks. Also, Rytting et al. (49) showed in 81 obese patients that after two years weight maintenance and drop out rates are independent of weather the initial treatment commences with VLCD (420 kcal/day for two months) or a hypocaloric diet $(1,600 \mathrm{kcal} /$ day $)$.

Saris (43) showed that VLCD in combination with active follow-up treatment is one of the better treatment modalities related to long-term weightmaintenance success. Also, two analysis concluded that greater initial weight loss using VLCDs is associated with better long-term weight maintenance. $(67,68)$ A meta-analysis of six studies showed that VLCDs induced significantly greater short-term weight losses than LCDs $(16.1+/-1.6 \%$ vs. $9.7+/-$ $2.4 \%$ of initial weight) but comparable long-term changes in weight $(6.3+/-3.2 \%$ vs. $5+/-4 \%)$. (48)

\section{Partial meal replacement}

Data showed that obese subjects underreport their actual food intake by $47 \%$ when consuming a diet of conventional foods and overreport their physical activity by $51 \%$. (69) Partial meal replacement (PMR) is defined as a program that prescribes one or two commercially available vitamin/mineral fortified meal (liquid or powder formulas) and at least one meal of regular foods. (70) A meta-analyses of six studies showed that a PMR plan compared to a conventional reduced calorie diet produced a significantly greater short-term and long-term weight loss. (71) Tovar et al. (72) found no additional effect of including PMR to a calorie restricted diet on changes in body weight, BMI or fat loss, than a LCD alone. In addition the authors showed that treatment of obesity with LCD that includes PMR significantly increased intake of essential amino acids, vitamins and minerals.

\section{Mediterranean diet}

The interest in the health implications of Mediterranean diet starts in the early 1950s with the results published by Ancel Keys. (73) The Mediterranean diet is characterized by a high consumption of vegetables, legumes, fruits, nuts, and cereals (preferably as whole grain); moderate consumption of fish and shellfish, white meat, dairy products and eggs; low consumption of read meat and moderate 
consumption of wine (during meals). $(74,75)$ The principal source of dietary lipids is olive oil. This diet is associated with an adequate intake of micronutrients. The Mediterranean diet, through a healthy profile of fat intake (with a high content of monounsaturated fatty acids - MUFA - and a higher MUFA/saturated fatty acids -SFA - ratio), low proportion of carbohydrate, low glycemic index, high content of dietary fiber, antioxidant compounds, and anti-inflammatory effects, is associated with a lower incidence of mortality from all-causes, and with a lower incidence of cardiovascular diseases, type 2 diabetes, certain types of cancer and neurodegenerative diseases. (74) Also, adherence to Mediterranean diet is associated with reduction of metabolic syndrome risk. $(76,77)$

Misirli et al. (75) demonstrated in 23,601 participants from the Greek segment of the EPIC Study which were free of cardiovascular diseases and cancer at baseline, followed up of about 10.6 years, an inverse association of adherence to the Mediterranean diet with cerebrovascular disease incidence and mortality. Zazpe et al. (78) demonstrated that a greater adherence to an empirically derived dietary pattern approaching the traditional Mediterranean diet was associated with a reduction in the risk of all cause mortality among middle-aged Mediterranean adults. Bonaccio et al. (79) showed in a prospective study on 1995 type 2 diabetic subjects that the traditional Mediterranean diet was associated with reduced risk of both total and cardiovascular mortality in diabetic subjects.

\section{Comparison of different weight loss diets}

Many studies evaluated the impact of the proportion of the macronutrients on weight loss and long-term metabolic control. Golay et al. (80) showed in 43 adult obese subjects that there was no significant difference in the amount of weight loss in response to diets containing either $15 \%$ carbohydrate $(8.4 \pm 0.6 \mathrm{~kg})$ or $45 \%$ carbohydrate $(7.5 \pm 0.5$ $\mathrm{kg}$ ) during a 6 weeks period of hospitalization. Both diets contained the same amount of energy $(1,000 \mathrm{kcal} /$ day $)$. In addition to a low-energy diet, subjects participated in a structured, multidisciplinary program that included physical activity, nutritional education and standard behavioral techniques. McLaughlin et al. (81) randomized 29 patients with diet treated type 2 diabetes to one of two equally hypocaloric ( $\sim 750 \mathrm{kcal} /$ day $)$ diets: 1$)$ moderately restricted fat $-60 \%$ carbohydrate, $25 \%$ fat and $15 \%$ protein and 2) moderately restricted in carbohydrate $-40 \%$ carbohydrate, $45 \%$ fat and
$15 \%$ protein. Both diets restricted saturated fat to $<7 \%$ of total calories. The results showed no significant difference in the amount of weight loss. Also the improvements in the metabolic variables (such as, insulin sensitivity, plasma glucose, insulin and triglyceride concentrations) were significantly associated with the amount of weight loss ( $7 \%)$ with no interaction with the diet. In a review published in 2013 Krabs (82) concluded that weight loss will not occur unless, energy intake is reduced below energy expenditure over a sustained period of time. Larsen et al. (83) evaluated the long-term efficacy (12 months) of high-protein diet (30\% energy intake from protein and $40 \%$ energy intake from carbohydrate) vs. a high carbohydrate diet (15\% energy intake from protein and 55\% energy intake from carbohydrate) in type 2 diabetic patients. The diets were matched for total fat $(30 \%$ of energy intake) and for fatty acid profile (7\% saturated fat, $10 \%$ polyunsaturated fat and $13 \%$ monounsaturated fat). This randomised controlled trial found that there is no superior long-term metabolic benefit of a high-protein diet over a high-carbohydrate diet.

Also, there are data which showed that the proportion of the macronutrients influence weight loss. (84-86) The Diet, Obesity and Geneses (Diogenes) study which included overweight participants from eight European countries evaluated the efficacy of moderate fat diets that vary in protein content and glycemic index for preventing weight regain after a 8 -week weight loss phase with the use of a 800 $\mathrm{kcal} /$ day diet (87). The mean weight loss with the low caloric diet was $11.2 \mathrm{~kg}$ (fat mass $-8.3 \mathrm{~kg}$ and fat-free mass $-2.9 \mathrm{~kg}$ ). The five weight maintenance diets on which the participants were randomized immediately after the completion of weight loss phase were: 1) a diet low in protein $(13 \%$ of total energy intake) with a low glycemic index; 2) a diet low in protein with a high glycemic index; 3) a diet high in protein ( $25 \%$ of total energy intake) with a low glycemic index; 4) a diet high in protein with a high glycemic index and 5) a control diet, which followed dietary guidelines in each participating country, with a moderat protein content and did not include instructions to participants regarding glycemic index. The difference in protein intake (from the total energy intake) between the high protein and the low protein groups that were achieved in the study was $5.4 \%$ and the difference between the low glycemic index and the high glycemic index was 4.7 glycemic index units. The study showed that after a 26 week weight maintenance phase in 548 participants who completed the 
intervention weight regain was only $0.56 \pm 5.44 \mathrm{~kg}$. The weight regain was less in the groups assigned to a high protein than those assigned to a low protein and in the groups assigned to a low glycemic index than in those assigned to a high glycemic index. The main conclusion of this large study was that a modest increase in protein content and a modest reduction in the glycemic index improved the maintenance of weight loss.

Ajala et al. (84) in a meta-analyses that included a total of 20 randomized controlled trials with intervention that lasted more than 6 months, evaluated the effect of various diets on glycemic control, lipids and weight loss in people with type 2 diabetes. The authors showed that low-carbohydrate, low-glycemic index (GI), Mediterranean and highprotein diets are effective in improving cardiovascular risk in people with diabetes. Low-carbohydrate, low-GI, Mediterranean and high-protein diets were associated with improvement in glycemic control, reduced $\mathrm{HbA} 1 \mathrm{c}$ by $0.12-0.5 \%$ compared with control diets including low-fat, high-GI, American Diabetes Association (ADA), European Association for the Study of Diabetes (EASD) and low-protein diets. Also, low-carbohydrate and Mediterranean diets led to a greater weight loss $(-0.69 \mathrm{~kg}, \mathrm{p}=0.21$ and $-1.89 \mathrm{~kg}, \mathrm{p}<0.00001)$ and all diets, except high-protein diet, were associated with an increase in HDL-cholesterol (4\% in Mediterranean, $5 \%$ in low-GI and 10\% in low-carbohydrate). Shai et al. (88) showed in a 24 months trial that a low-carbohydrate diet has more favorable effect on lipids and Mediterranean diet has more favorable effect on glycemic control.

\section{Possible future directions}

The human intestinal tract is populated by approximately $10^{14}$ microorganisms (known as the „gut microbiota“), most of them anaerobic bacteria, composed by approximately 1,000 bacterial species with significant intersubject variability. (8991) This huge number of bacterial species can be grouped into 2 bacterial phyla: the Bacteroidetes (Gram-negative) and the Firmicutes (Gram-positive). $(89,91)$ The collective genome of the gut microbiota (known as the gut "microbiome“) contains at least 100 times as many genes as the human genome. (90) Human gut colonization begins immediately at birth and evolves throughout an individual's lifetime and is susceptible to both exogenous and endogenous modifications. (92) Microbiota has multiple roles in host physiology, energy regulation and modulation of immune function. (91,93-95)
Microbiota increases the host's ability to extract energy from the ingested nutrients and the storage of this energy as fat contributing to body-weight gain. $(93,95)$ Alterations in gut microbiota is associated with numerous intestinal diseases such as, irritable bowel syndrome, inflammatory bowel disease and colorectal cancer and also may influence the development and progression of obesity and other metabolic disorders, including type 2 diabetes. $(93,94,96,97)$ The impact of the gut microbiota on metabolic disorders is realized through systemic exposure to bacterial lipopolysacharide (LPS), as a result of increased intestinal permeability. $(118,120)$ Cani et al. (98) in an article published in 2007 on mice had three important results: first, a 4-week high-fat diet chronically increases plasma LPS concentration two to three times (threshold named metabolic endotoxemia); second, chronic experimental metabolic endotoxemia induces obesity, diabetes and liver insulin resistance and third, the LPS receptor CD14, by controlling insulin sensitivity, sets the threshold at which high-fat diet-induced metabolic diseases occur.

Gut microbiota composition has been shown to differ in lean vs. obese animals and humans and to change rapidly in response to diet. $(95,99)$ Also, weight loss programs and gastric by-pass surgery are associated with modifications of gut microbiota. (100) The gut bacterial flora of obese mice and humans include fewer Bacteroidetes and more Firmicutes compared to their lean counterparts. $(93,101,102)$ Recent data showed that butyrateproducing bacteria such as Roseburia intestinalis and Faecalibacterium prausnitzii concentrations are lower in type 2 diabetes $(91,103)$. Manipulation of the gut microbiota by using antibiotics, probiotics and prebiotics may represent a novel approach for treating obesity $(101,104,105)$. Probiotics are defined as live microorganisms, that when administered in adequate amounts confer a health benefit on the host (106), while prebiotics are defined as selectively fermented ingredients that allow specific changes, both in the composition and/or activity in the gastrointestinal microflora that confer benefits upon host well being and health. (107) In a recent study on mice published in 2014 Cox et al. (108) showed that the administration of low-dose penicillin in early life induces long-term metabolic effects by altering the intestinal microbiota. In humans, more studies showed that cesarean section was associated with offspring overweight and obesity, perhaps as a result of changes in gut microbiota. $(109,110)$ Ajslev et al. (111) showed that a combination of delivery mode, maternal pre-pregnancy 
BMI and antibiotics in infancy, influences the risk of overweight in late childhood. Kellow et. al. (112) showed in a review which included 26 randomised controlled trials involving 831 participants that dietary prebiotic consumption was found to be associated with subjective improvements in satiety and reductions in postprandial glucose and insulin concentrations. Moroti et al. (113) showed on 20 type 2 diabetic patients that the consumption of a symbiotic shake containing Lactobacillus acidophilus, Bifidobacterium bifidum and fructooligosachharides was associated with a significant increase in HDL-cholesterol and a significant reduction in fasting glycemia. Ma et al. (114) showed in a review of four randomized trails which included 134 patients with non alcoholic fatty liver disease that treatment with probiotics was associated with reduction in liver aminotransferases, total-cholesterol, TNF- $\alpha$ and improve insulin resistance. Data showed that metformin modulate the gut microbiota. $(91,115)$

\section{DISCUSSION}

Numerous diets have been used for the nutritional treatment of patients with type 2 diabetes. Because there is no optimal diet for diabetic patients nutritional counseling must be individualized. Data showed that lifestyle-modification program characterized by an increase in physical activity and a balanced diet can reduce obesity and the risk of obesity-related comorbid conditions despite minimal or no weight loss. The benefits of such an approach are: appreciable reductions in abdominal obesity, visceral fat and cardiometabolic risk factors, and increases in both skeletal muscle mass and cardiorespiratory fitness. (116) Also recent released guidelines consider that overweight and obesity should be managed as a long term chronic disease. (25) Dombrowaki et al. (117) showed in a meta-analysis which included 45 trials involving 7,788 subjects that a behavioural interventions targeting both dietary and physical activity are moderately effective in reducing weight regain after initial weight loss in obese adults.

It is difficult to compare the results of the studies which evaluated the effects of different diets in obese type 2 diabetic patients due to variable macronutrient and caloric composition, difficulty in accurately measuring dietary intake, various behavioural change interventions and differences between highly controlled studies and free living studies. (118)

In short-term trials low-carbohydrate/high-protein diets diet are more favourable for weight loss than traditional high-carbohydrate, low-fat diets. $(37,83)$ International societies such as American Heart Association don't recommend high-protein diets for weight loss because people who stay on these diets very long may not get enough vitamins, minerals and fiber and face other potential health risks (119). According to American Diabetes Association (24) there is no single dietary patterns for diabetic patients, personal preferences (tradition, culture, religion, health beliefs, economics) and metabolic goals should be considered when recommending one eating pattern over another (Mediterranean style, vegetarian, low fat, low carbohydrate, Dietary Approaches to Stop Hypertension DASH).

Larger and long-term randomized control trials are needed to compare relative efficacy and effectiveness of various dietary approaches. (120) Selection of an inadequate diet could give rise to serious complications: deficiencies in various types of micronutrients, worsening of the cardiovascular risk, development of serious eating disorders, misconceptions about obesity and its treatment, stimulation of a feeling of frustrations, changes in energy metabolism which result in ,resistance“ to weight loss. (121)

There are data which showed that the degree of adherence to a dietary program and not the composition of the diet is the principal effect associated with a better outcome. (122) To facilitate compliance to different diets in many studies participants were provided with individualized advice by a registered dietician, diet plans and food-exchange options (123). Korre et al. (124) discuss the importance of the interventions which have tried to change worksites eating habits. Salinardi et al. (125) reported that a two phases worksite intervention program on weight loss (a 6 months weighloss phase, which had the goal to achieve a weightloss of $0.5-1 \mathrm{~kg} /$ week and a 6 months weighmaintenance phase) in overweight and obese adults was effective in body weight reduction and improvement of cardiometabolic risk factors. Participants in the intervention group lost $8 \pm 0.7 \mathrm{~kg}$, compared with the control participants who gained $0.9 \pm 0.5 \mathrm{~kg}$. It is important to emphasise that $89 \%$ of participants completed the weight-loss phase and no significant weight regain was observed in participants enrolled in the structured weight-maintenance phase. The program used portion-controlled menus that contained $\geq 40$ g dietary fiber/ day, $25 \%$ of calories from protein, $27 \%$ from fat and $48 \%$ from low-glycemic index carbohydrates. Future studies are necessary to evaluate if dietary 
strategies targeting the gut flora (such as, administration of probiotics and prebiotics) are useful to control metabolic disorders.

The newly released guideline by the Endocrine Society (126) regarding pharmacological management of obesity recommend that diet, exercise and behavioral modification should be included in all obesity management approaches for BMI $\geq 25 \mathrm{~kg} /$ $\mathrm{m}^{2}$ and pharmacotherapy should be used as adjunct to behavioral modification in subjects with BMI $\geq 27 \mathrm{~kg} / \mathrm{m}^{2}$ and at least one associated comorbid medical condition such as hypertension, dyslipidemia, type 2 diabetes and obstructive sleep apnea or BMI $>30 \mathrm{~kg} / \mathrm{m}^{2}$. Bariatric surgery is recommended in subjects with BMI $\geq 35 \mathrm{~kg} / \mathrm{m}^{2}$ with comorbidity or BMI $>40 \mathrm{~kg} / \mathrm{m}^{2}$. With the exception of orlistat which block fat absorbtion, anti-obesity drugs target appetite mechanisms. The drugs approved by FDA for weight management are: for short-term use (3 months) - norepinephrine-releasing agents such as phentermine and diethylpropion and for chronic use - orlistat, lorcaserin $\left(5 \mathrm{HT}_{2 \mathrm{C}}\right.$ receptor agonist, marketed as Belviq), phentermine/ topiramate (norepinephrine-releasing agent/modification of excitatory voltage-activated sodium and calcium channels, antagonism of alpha-amino3-hydroxyl-4-isoxazole-propionic acid kainate AMPA/KA- and GABA receptor modulation, marketed as Qsymia), naltrexone/bupropion (opioid antagonist/reuptake inhibitor of dopamine and norepinephrine, marketed as Contrave), liraglutide (GLP-1 agonist, marketed as Saxenda). (126-128) Due to safety concerns orlistat was the only drug available for the treatment of obesity in Europe until this year. Recently the European Commission has approved two anti-obesity drugs: liraglutide and naltrexone/bupropion (marketed as Mysimba). (129)

\section{REFERENCES}

1. Therapy for diabetes mellitus and related disorders $6^{\text {th }}$ ed, American Diabetes Association, 2014.

2. Prospective Studies Collaboration: Body-mass index and causespecific mortality in 900000 adults: collaborative analyses of 57 propsective studies. Lancet, 2009; 373 (9669): 1083-1096.

3. Cerhan J.R., Moore S.C., Jacobs E.J., Kitahara C.M. et al. A pooled analysis of waist circumference and mortality in 650,000 adults. Mayo Clin Proc, 2014; 89(3):335-45.

4. Wharton S., Sharma A.M., Lau D.C.W. Weight management in diabetes. Canadian Diabetes Association clinical practice guidelines expert committee. Can J Diabetes, 2013; 37 (Suppl 1): S82-S86.

5. Dworatzek P.D., Arcudi K., Sougeon R. et al. Clinical Practice Guidelines. Nutrition Therapy. Can J Diabetes, 2013; 37: S45-S55.

6. Franz M.J., Boucher J.L., Evert A.B. Evidence-based diabetes nutrition therapy recommendations are effective: the key is individualization. Diabetes, Metabolic Syndrome and Obesity: Targets and Therapy, 2014; 7: 65-72.

7. Baker S., Jerums G., Proietto J. Effects and clinical potential of very-low-calorie diets (VLCDs) in type 2 diabetes. Diab Res Clin Pract, 2009; 85(3): 235-242.

8. Petersen K.F., Dufour S., Befroy D. et al. Reversal of nonalcoholic hepatic steatosis, hepatic insulin resistance, and hyperglycemia by moderate weight reduction in patients with type 2 diabetes. Diabetes, 2005;54(3):603-608.

9. Henry R.R., Scheaffer .L, Olefsky J.M. Glycemic effects of intensive caloric restriction and isocaloric refeeding in noninsulindependent diabetes mellitus. J Clin Endocrinol Metab, 1985; 61(5):917-925.

10. Meinders A.E., Pijl H. Very low calorie diets and recently developed anti-obesity drugs for treating overweight in non-insulin dependent diabetics. Int J Obes Relat Metab Disord, 1992; 16 (Suppl 4): S35-S39.

11. Williamson D.F., Thompson D.J., Thun M. et al. Intentional weight loss and mortality among overweight individuals with diabetes. Diabetes Care 2000; 23(10): 1499-1504.

12. Feldstein A.C., Nichols G.A., Smith D.H. et al. Weight change in diabetes and glycemic and blood pressure control. Diabetes Care, 2008; 31(10): 1960-1965.

13. Jensen M.D., Ryan D.H., Apovian C.M. et al. American College of Cardiology/American Heart Association Task Force on Practice Guidelines; Obesity Society: 2013 AHA/ACC/TOS guideline for the management of overweight and obesity in adults: a report of the American College of Cardiology / American Heart Association task force on practice guidelines and The Obesity Society. Circulation, 2014; 129 (25 Suppl 2): S102-138.

14. The Look AHEAD Research Group: Eight-year weight losses with an intensive lifestyle intervention: the Look AHEAD study. Obesity, 2014; 22(1): 5-13.

15. www.lookaheadtrial.org.

16. The Look AHEAD Research Group: Cardiovascular effects of intensive lifestyle intervention in type 2 diabetes. N Engl J Med, 2013; 369: 145-154.

17. Gregg E.W., Chen H., Wagenknecht L.E. et al. for the Look AHEAD Research Group: Association of an intensive lifestyle intervention with remission of type 2 diabetes. JAMA, 2012; 308 (23): 2489-2496.

18. Foster G.D., Borradaile K.E., Sanders M.H. et al. and the Sleep AHEAD Research Group of the Look AHEAD Research Group: A randomized study on the effect of weight loss on obstructive sleep apnea among obese patients with type 2 diabetes: the Sleep AHEAD study. Arch Intern Med, 2009; 169(17): 1619-1626.

19. Rejeski W.J., Ip E.H., Bertoni A.G. et al. Look AHEAD Research Group: Lifestyle change and mobility in obese adults with type 2 diabetes. N Engl J Med, 2012; 366(13): 1209-17.

20. Williamson D.A., Rejeski J., Lang W. et. al for the Look AHEAD Research Group: Impact of a weight management program on health-related quality of life in overweight adults with type 2 diabetes. Arch Intern Med 2009; 169(2):163-71.

21. Diabetes Prevention Program Research Group: Reduction in the incidence of type 2 diabetes with lifestyle intervention or metformin. N Engl J Med, 2002; 346: 393-403.

22. Li G., Zhang P., Wang J., An Y. et al. Cardiovascular mortality, all-cause mortality, and diabetes incidence after lifestyle intervention for people with impaired glucose tolerance in the Da Qing Diabetes Prevention Study: a 23-year follow-up study. The Lancet Diabetes \& Endocrinology, 2014; 2(6): 474-480. 
23. Mann J.I., De Leeuw I., Hermansen K. et al. Diabetes and Nutrition Study Group (DNSG) of the European Association: Evidence-based nutritional approaches to the treatment and prevention of diabetes Mellitus. Nutr Metab Cardiovasc Dis, 2004; 14(6): 373-394.

24. Evert A.B., Boucher J.L., Cypress M. et al. Nutrition therapy recommendations for the management of adults with diabetes. Diabetes Care, 2014; 37 (suppl. 1): S120-S153.

25. Gonzalez-Campoy J.M., Jeor S.T.S, Castorino K. et al. American Association of Clinical Endocrinologists; American College of Endocrinology and the Obesity Society: Clinical practice guidelines for healthy eating for the prevention and treatment of metabolic and endocrine diseases in adults: cosponsored by the American Association of Clinical Endocrinologists / the American College of Endocrinology and the Obesity Society. Endocrine Practice, 19 (Suppl. 3): 1-82.

26. Dayson P.A., Kelly T., Drakin T. et al on behalf of Diabetes UK Nutrition Working Group: Diabetes UK evidence-based nutrition guidelines for the prevention and management of diabetes. Diabet. Med, 2011; 28: 1282-1288.

27. Nutrition Subcommittee of the Diabetes Care Advisory Committee of Diabetes UK: The implementation of nutritional advice for people with diabetes. Diabet. Med, 2003; 20: 786-807.

28. Friedman A.N., Ogden L.G., Foster G.D. et al. Comparative effects of low-carbohydrate high-protein versus low-fat diets on the kidney. Clin J Am Soc Nephrol, 2012; 7(7): 1103-111.

29. Foster G.D., Wyatt H.R., Hill J.O. et al. A randomized trial of low carbohydrate diet for obesity. N Engl J Med, 2003; 348(21): 2082-2090.

30. Santesso N., Akl E.A., Mente A. et al. Effects of higher-versus lower-protein diets on health outcomes: a systematic review and meta-analysis. Eur J Clin Nutr, 2012; 66(7): 780-788.

31. Gannon M.C., Nuttall F.Q. Effect of a high-protein low-carbohydrate diet on blood glucose control in people with type 2 diabetes. Diabetes, 2004; 53(9): 2375-2382.

32. Pesta D.H., Samule V.T. A high-protein diet for reducing body fat mechanisms and possible caveats. J Nutr Metab, 2014; 11:53.

33. Veldhorst M.A., Westerterp K.R., Westerterp-Plantenga M.S. Gluconeogenesis and protein-induced satiety. Br J Nutr, 2012, 107(4): 595-600.

34. www.diabetes.org.uk/About_us/What-we-say/Food-nutrition-lifestyle/ Low-carbohydrate-diets-for-people-with -Type-2-diabetes/

35. American Diabetes Association: Nutrition recommendations and intervention for diabetes. A position statement of the American Diabetes Association. Diabetes Acre, 2008; 31 (Suppl. 1): S61-S78.

36. Wheeler M.L., Dunbar S.A., Jaacks L.M. et al. Macronutrients, food groups and eating patterns in the management of diabetes. A systematic review of the literature, 2010. Diabetes Acre, 2012; 35: 434-445.

37. Accurso A., Bernstein R.K., Dahlqvist A. et al. Dietary carbohydrate restriction in type 2 diabetes mellitus and metabolic syndrome: time for a critical appraisal. Nutrition and Metabolism, 2008, 5:9.

38. Nielssen J.V., Jonsson E., Nilsson A.K. Lasting improvement of hyperglycaemia and bodyweight: low-carbohydrate diet in type 2 dibetes. Ups J Med Sci, 2005; 110(2): 179-83.

39. Nielsen J.V., Joensson E.A. Low-carbohydrate diet in type 2 diabetes: stable improvement of bodyweight and glycemic control during 44 month follow-up. Nutrition \& Metabolism, 2008; 5:14.

40. Guldbrand H., Dizdar B., Bunjaku B. et al. In type 2 diabetes, randomisation to advice to follow a low-carbohydrate diet transiently improves glycaemic control compared with advice to follow a low-fat diet producing a similar weight loss. Diabetologia, 2012; 55 : 2118-2127.

41. Spritzler F. A low-carbohydrate, whole-foods approach to managing diabetes or prediabetes. Diabetes Spectrum, 2012; 25(4): 238-243.

42. Swedish Council on Health Technology Assessment. Report: Dietary treatment of obesity. A systematic review, Sep 2013. available at: www.sbu.se/upload/Publikationer/Content1/1/Dietary_treatment_ obesity.pdf. accesed on 01.02.2015.
43. Saris W.H. Very-low-calorie diets and sustained weight loss. Obes Res, 2001; 9(Suppl 4): 295S-301S.

44. Dhindsa P., Scott A.R., Donnelly R. Metabolic and cardiovascular effects of very-low-calorie diet therapy in obese patients with type 2 diabetes in secondary failure: outcomes after 1 year. Diabet Med, 2003; 20: 319-324.

45. Rolland L., Broom I. The effects of very-low-caloric diets on HDL: an overview. Cholesterol, 2011, ID: 366278, 10 pages.

46. AACE/ACE Obesity Task Force: AACE/ACE position statement on th prevention, diagnosis and treatment of obesity. Endocrine Practice, 1998; 4(5): 297-350.

47. Obesity and management of overweight and obesity in children, young people and adult. available at www.nice.org.uk/guidance/ cg189NICE clinical guideline 189, accessed on 10.02.2015.

48. Tsai A.G., Wadden T.A. The evolution of very-low-calorie diets: an update an meta-analysis. Obesity, 2006; 14(8): 1283-1293.

49. Rytting K.R., Flaten H., Rosmer S. Long-term effects of a very low calorie diet (Nutrilett) in obesity treatment. A prospective, randomized comparison between VLCD and a hypocaloric diet + behaviour modification and their combination. Int $\mathrm{J}$ Obes Relat Metab Disord, 1997; 21(7): 574-579.

50. National Task Force on the Prevention and Treatment of Obesity. Very low-calorie diets. JAMA, 1993; 270: 967-974.

51. National Institute for Health and Clinical Excellence and National Collaborating Centre for Primary Care: Obesity: the prevention, identification, assessment and management of overweight and obesity in adults and children. Available at www.nice.org.uk/ nicemedia/CG43FinalGuideline1.doc.

52. Assessment of very low calorie diets. Opinion of the Panel on nutrition, dietetic products, novel food and allergy of the Norwegian Scientific Committee for Food Safety. Available at www.vkm.no/dav/ c3ce7944de.pdf.

53. European Food Safety Authority. Scientific opinion on the substantiation of health claims related to very low calorie diets (VLCDs) and reduction in body weight (ID 1410), reduction in the sense of hunger (ID 1411), reduction in body fat mass while maintaining lean body mass (ID 1412), reduction of post-prandial glycaemic responses (ID 1414), and maintenance of normal blood lipid profile (1421) pursuant to Article 13(1) of Regulation (EC) No 1924/2006. EFSA Journal. 2011; 9(6):2271-2293.

54. National Task Force on the Prevention and Treatment of Obesity. Very low-calorie diets. JAMA, 1993; 270: 967-974.

55. Capstick F., Brooks B.A., Burns C.M. et al. Very low calorie diet (VLCD): a useful alternative in the treatment of the obese NIDDM patient. Diabetes Rec Clin Pract, 1997; 36(2): 105-111.

56. Malandrucco I., Pasqualetti P., Giordani I. et al. Very low calorie diet: a quick therapeutic tool to improve beta cell function in morbidly obese patients with type 2 diabetes. Am J Clin Nutr 2012; 95(3): 609-13.

57. Preis S.R., Stampfer M.J., Spiegelman D. et al. Lack of association between dietary protein intake and risk of stroke among middle-aged men. Am J Clin Nutr 2010; 91 (1):39-45.

58. Rolland C., Broon I. The effects of very-low-calorie diets on HDL: a review. Cholesterol, 2011; ID: 306278.

59. Hammer S., Snel M., Lamb H.J., Jazet I.M. et al. Prolonged caloric restriction in obese patients with type 2 diabetes mellitus decreases myocardial triglyceride content and improves myocardial function. JACC, 2008; 52(12); 1006-1012.

60. Foster G.D., Wadden T.A., Peterson F.J. et al. A controlled comparison of three very low calorie diets: effects on weight, body composition and symptoms. Am J Clin Nutr, 1992; 55(4): 811-817.

61. Rössner S., Flaten H. VLCD versus LCD in long-term treatment of obesity. International Journal of Obesity, 1997; 21 (1): 22-26.

62. Lin W.-Y., Wu C.-H., Chu N.-F. et al. Efficacy and safety of very-low-calorie diet in Taiwanese: a multicenter randomized, controlled trial. Nutrition, 2009; 25, (11-12): 1129-1136.

63. Johansson K., Sundstrom J., Marcus C. et al. Risk of symptomatic gallstones and cholecistectomu after a very-low-calorie diet or low-calorie diet in a commercial weight loss program: 1-year matched cohort study. Int J Obes, 2014; 38(2): 279-284. 
64. Dhindsa P., Scott A.R., Donnelly R. Metabolic and cardiovascular effects of very-low-calorie diet therapy in obese patients with type 2 diabetes in secondary failure: outcomes after 1 year. Diabet Med, 2003; 20(4): 319-324.

65. Hemmingsson E., Johansson K., Eriksson J. et al. Weight loss and dropout during a commercial weight-loss program including a very low-calorie diet, a low-calorie diet, or restricted normal food: observational cohort study. Am J Clin Nutr, 2012; 96(5): 953-961.

66. Purcell K., Sumitthran P., Prendergast L.A. et al. The effect of rate of weight loss on long-term weight management: a randomized controlled trial. The Lancet Diabetes \& Endocrinology, published online October 2014

67. Anderson J.W., Konz E.C., Frederich R.C. et al. Longterm weight-loss maintenance: a meta-analysis of US studies. Am J Clin Nutr, 2001;74 (5):579-84.

68. Astrup A., Rossner S. Lessons from obesity management programmes: greater initial weight loss improves long-term maintenance. Obes Rev. 2000;1:17-19.

69. Lichtman S.W., Pisarska K., Berman E.R. et al. Discrepancy between self-reported and actual caloric intake and exercise in obese subjects. N Engl J Med, 1992; 327 (27): 1893-1898.

70. Cabanillas M., Moya Chimenti E., Gonzalez Candela C. et al. Usefulness of meal replacement: analysis of the principal meal replacement products commercialised in Spain. Nutr Hosp Organo Oficial Soc Esp Nutr Parenteral y Enteral 2009; 24(5): 535-542.

71. Heymsfield S.B., van Mierlo C.A., van der Knaap H.C. et al. Weight management using a meal replacement strategy: meta and pooling analysis from six studies. Int J Obes, 2003; 27: 537-549

72. Tovar A.R., Caamano M.D., Garcia-Padilla S. et al. The inclusion of a partial meal replacement with or without inulin to a calorie restricted diet contributes to reach recommended intakes of micronutrients and decrease plasma triglycerides: a randomized clinical trial in obese Mexican women. Nutr J 2012; 11: 44.

73. Nestel M. Mediterranean diets: historical and research overview. Am J Clin Nutr, 1995; 61 (Suppl): 1313S-1320S

74. Castro-Quezada I., Roman-Vinas B., Serra-Majem L. The medierrean diet and nutritional adequacy: a review. Nutrients, 2014; 6(1): 231-248.

75. Misirli G., Benetou V., Lagiou P. et al. Relation of the Traditional Mediterranean Diet to Cerebrovascular Disease in a Mediterranean Population. Am J Epidemiol, 2012; 176 (12): 1185-1192.

76. Kesse-Guyot E., Ahluwalia N., Lassale C. et al. Adherence to Mediterranean diet reduces the risk of metabolic syndrome: a 6-year prospective study. Nutr Metab Cardiovasc Dis, 2013; 23(7): 677-683

77. Garcia-Fernandez E., Rico-Cabanas L., Rosgaard N. et al. Mediterranean diet and cardiodiabesity: a review. Nutrients, 2014; 6: $3474-3500$

78. Zazpe I., Sanchez-Tainta A., Toledo E. et al. Dietary patterns and total mortality in a Mditerranean cohort: the SUN project. J Acad utr Diet, 2014; 114(1); 37-47

79. Bonaccio M., Di Castelnuovo A., Costanzo S. et al on behalf of the MOLI-SANI study investigators: Adherence to the traditional Mediterranean diet and mortality in subjects with diabetes: Preospective results from the MOLI-SANI study. Eur J Prev Cardiol, 2015; PMID 25648935

80. Golay A., Allaz A.F., Morel Y., de Tonnac N. et al. Similar weight loss with low- of high- carbohydrate diets. Am J Clin Nutr, 1996; 63: 174-178.

81. McLaughlin T., Carter S., Lamendola C. et al. Clinical efficacy of two hypocaloric diets that vary in overweight patients with type 2 diabetes. Comparison of moderate versus carbohydrate reductions. Diabetes Care, 2007; 30 (7): 1877-1879

82. Krabs J.D., Parry-Strong A. Is there an optimal diet for patients with type 2 diabetes? Yes, the one that works for them. British Journal of Diabetes and Vascular Disease, 2013; 13:60-66.

83. Larsen R.N., Mann N.J., Maclean E., et al. The effect of highprotein, low-carbohydrate diets in the treatment of type 2 diabetes: a 12 month randomized controlled trial. Diabetologia, 2011; 54:731740.
84. Ajala O., English P., Pinkney J. Systematic review and metaanalysis of different dietary approaches to the management of type 2 diabetes. Am J Clin Nutr, 2013, 2013; 97: 505-516

85. McDougall J., Thomas L.E., McDougall C. et al. Effects of 7 days on an ad libitum low-fat vegan diet: the McDougall Program Cohort. Nutrition Journal, 2014; 13: 99, 7 pages.

86. Viguiliouk E., Kendal C.W.C., Meja S.B. et al. PLos ONE, 2014; 9(7): e103376

87. Larsen T.M., Dalskov S.M., van Baak M. et al for the Diet, Obesity, and Genes (Diogenes) Project: Diets with high or low protein content and glycemic index for weight loss maintenance. N Engl J Med, 2010; 363(22): 2102-2113

88. Shai l., Schwarzfuchs D., Henkin Y. et al for the Dietary Intervention Randomized Controlled Trial (DIRECT) Group: Weight loss with a low-carbohydrate, Mediterranean, or low-fat diet. $N$ Engl J Med, 2008; 359 (3): 229-241.

89. Eckburg P.B., Bik E.M., Bernstein C.N. et al. Diversity of the human intestinal microbial flora. Science 2005; 308(5728): 1635-1638

90. Gill S.R., Pop M., Deboy R.T. et al. Metagenomic analysis of the human distal gut microbiome. Science 2006; 312 (5778): 1355-1359

91. Allin K.H., Nielsen T., Pedersen O. Gut microbiota in patients with type 2 diabetes mellitus. Eur J Endocrinol, 2015; 172 (4): R167-R177

92. Sekirov I., Russel S.L., Antunes C.M. et al. Gut microbiota in health and disease. Physiol Rev, 2010; 90:859-904

93. Sanz Y., Santacruz A., Gauffin P. Probiotics in the defence and metabolic balance of the organism. Gut microbiota in obesity and metabolic disorders. Proceedings of the Nutrition Society, 2010; 69: 434-441.

94. Guinane C.M., Cotter P.D. Role of the gut microbiota in health and chronic gastrointestinal disease: understanding a hidden metabolic organ. Ther Adv Gastroenterol, 2013; 6(4): 295-308

95. DiBaise J.K., Frank D.N., Mathur R. Impact of the gut microbiota on the development of obesity : Current Concepts. Am J Gastroenterol Suppl, 2012; 1:22-27

96. DiBaise J.K., Frank D.N., Mathur R. Impact of the gut microbiota on the development of obesity: current concepts. $A m \mathrm{~J}$ Gastroenterol, 2012 (Suppl); 1: 22-27

97. Gomez A.C., Bueno A.A., de Souza R.G.M. et al. Gut microbiota, probiotics and diabetes. Nutrition Journal, 2014; 13: 60; 13 pages

98. Cani P.D., Amar J., Iglesias M.A. et al. Metabolic endotoxemia initiates obesity and insulin resistance. Diabetes 2007, 56(7): $1761-1772$.

99. Jumpertz R., Le D.S., Turnbaugh P.J. et al. Energy-balance studies reveal associations between gut microbes, caloric load and nutrient absorbtion in humans. Am J Clin Nutr, 2011; 94(1): 58-65

100. Krajmalnik-Brown R., Ilhan Z.E., Kang D.W., DiBaise J.K. Effects of gut microbes on nutrient absorbtion and energy regulation. Nutr Clin Pract, 2012; 27(2): 201-214

101. DiBaise J.K., Zhang H., Crowell M.D. et al. Gut microbiota and its possiblerelationship with obesity. Mayo Clin Proc, 2008; 83(4): 460-469.

102. Kallus S.J., Brandt L.J. The intestinal microbiota and obesity. J Clin Gastroenterol, 2012; 46(1): 16-24

103. Moschen A.R., Tilg H. Microbiota and diabetes: an evolving relationship. Gut, 2014; 63(9): 1513-1521.

104. Jess T. Microbiota, antibiotics and obesity. N Engl J Med, 2014; 371(26): 2526-2528

105. Delzenne N.M., Neyrinch A.M., Backhead F. et al. Targeting gut microbiota in obesity: effects of prebiotics and probiotics. Nature Review Endocrinology, 2011; 7(11): 639-646

106. Sanders M.E. Probiotics: definition, sources, selection and use. Clin Infect Dis, 2008; 46 (Suppl 2): S58-S61.

107. Gibson G.R., Probert H.M., Van Loo J.A.E. et al. Dietary modulation of the human colonic microbiota: Updating the concept of prebiotics. Nutr Res Rev. 2004; 17(2):257-9.

108. Cox L.M., Yamanishi S., Sohn J. et al. Altering the intestinal microbiota during a critical developmental window has lasting metabolic consequences. Cell 2014;158(4): 705-721. 
109. Li H.T., Zhou Y.B., Liu J.M. The impact of cesarean section on offspring overweight and obesity: a systematic review and metaanalysis Int J Obes (Lond), 2013;37(7):893-899

110. Goldani M.Z., Barbieri M.A., Moura da Silva A. et al. Cesarean section and increased body mass index in school children: two cohort studies from distinct socioeconomic background areas in Brasil. Nutrition Journal, 2013; 12: 104, 7 pages

111. Ajslev T.A., Andersen C.S., Gamborg M. et al. Childhood overweight after establishment of the gut microbiota: the role of delivery mode, pre-pregnancy weight and early administration of antibiotics. Int J Obes (Lond) 2011;35(4):522-9.

112. Kellow N.J., Coughlan M.T., Reid C.M. Metabolic benefits of dietary prebiotics in human subjects: a systematic review of randomized controlled trials. British Journal of Nutrition, 2014; 111(7): 1147-1161.

113. Moroti C., Souza Magri L.F., de Resende Costa M. et al. Effect of the consumption of a new symbiotic shake on glycemia and cholesterol levels in elderly with type 2 diabetes. Lipids Health Dis, 2012; 11:29

114. Ma Y.Y., Li L., Yu C.H. et al. Effects of probiotics on nonalcoholic fatty liver disease: A meta-analysis. World J Gastroenterol, 2013; 19(40): 6911-6918

115. Shin N.R., Lee J.C., Lee H.Y. et al. An increase in the Akkermansia spp. population induced by metformin treatment improves glucose homeostasis in diet-induced obese mice. Gut, 2014; 63(5): 727-735

116. Ross R., Bradshow A.J. The future of obesity reduction: beyond weight loss. Nat Rev Endocrinol, 2009; 5: 319-325

117. Dombrowski S.U., Knittle K., Avenell A. et al. Long term maintenance of weight loss with non-surgical interventions in obese adults: systematic review and meta-analyses of randomised controlled trials. BMJ, 2014;348:g2646. doi:10.1136/bmj.g2646.

118. Krabs J.D., Parry-Strong A. Is there an optimal diet for patients with type 2 diabetes? Yes, the one that works for them. British Journal of Diabetes and Vascular Disease, 2013; 13:60-66.
119. www.heart.org/HEARTORG/GettingHealthy/NutritionCenter/ High-Protein-Diets_UCM_305989_Article.jsp, accessed on 13.04.2015

120. Ley S.H., Hamdy O., Mohan V., Hu F.B. Prevention and management of type 2 diabetes: dietary components and nutritional strategies. Lancet, 2014; 383 (9933): 1999-2007.

121. Manuel M.G.F., Lesmes I.B., Morset J.B. et al. FESNAD-SEEDO consensus group: Evidence based nutritional recommendations for the prevention and treatment of overweight and obesity in adults (FESNAD-SEEDO consensus document). The role of diet in obesity treatment. Nutr Hosp, 2012; 27(3): 833-864.

122. Bray G.A. Lifestyle and pharmacological approaches to weight loss: efficacy and safety. J Clin Endocrinol Metab, 2008; 93 (11 Suppl 1): p. S81-88.

123. Tay J., Luscombe-Marsh N.D., Thompson C.H. et al. A very low carbohydrate, low saturated fat diet for type 2 diabetes management: a randomized trial. Diabetes Care, 2014; published online July 28.

124. Korre M., Tsoukas M.A., Frantzeskou E. et al. Mediterranean diet and workplace health promotion. Curr Cardiovasc Risk Rep, 2014; 8:416

125. Salinardi T.C., Batra P., Roberts S.B. et al. Lifestyle intervention reduces body weight and improves cardiometabolic risk factors in worksites. Am J Clin Nutr, 2013; 97(4): 667-676

126. Apovian C.M., Aronne L.J., Bessesen D.H. et al. Pharmacological management of obesity: an Endocrine Society clinical practice guideline. J Clin Endocrinol Metab, 2015; 100(2): 342-362.

127. Shin J.H., Gadde K.M. Clinical utility of phentermine/topiramate (Qsymia) combination for the treatment of obesity. Diabetes Metab Syndr Obes, 2013; 6: 131-139

128. Kin G.W., Lin J.E., Blomain E.S. et al. Anti-obesity pharmacotherapy: new drugs and emerging targets. Clin Pharmacol Ther, 2014; 95(1): 53-66.

129. Naltrexone/Bupropion approved as Mysimba for obesity in EU available at www.medscape.com/viewarticle/842166, accesed on 28.03.2015. 